\title{
Studies on the Pasting and Rheology of Rice Starch with Different Protein Residual
}

\author{
Qinlu Lin ${ }^{1, *}$, ZhongHua Liu ${ }^{2}$, Huaxi Xiao ${ }^{1}$, Lihui ${ }^{1}{ }^{1}$, Fengxiang $\mathrm{Yu}^{1}$, and Wei Tian ${ }^{2}$ \\ ${ }^{1}$ Faculty of Food Science and Engineering, Center South University of Forestry and Technology, \\ Changsha, Hunan Province, P.R. China 410004 \\ lq10403@yahoo.com.cn \\ ${ }^{2}$ Faculty of Food Science and Technology, Hunan Agricultural University, \\ Changsha, Hunan Province, P.R. China 410004
}

\begin{abstract}
Indica rice starch and japonica rice starch were used in the study. The protein contents of the two rice variety were respectively $0.43 \%, 0.62 \%$, $0.84 \%, 1.08 \%, 1.25 \%$. The pasting and rheological properties of samples were determined with Rapid Visco Analyzer and dynamic rheometer. The results indicated that, with the increase of protein content, the peak viscosity, breakdown viscosity and final viscosity of rice starch paste decreased, the setback viscosity increased and the pasting temperature did not change significantly. With the increase of protein content, the consistency coefficient of starch decreased, the corresponding yield stress also decreased, however, the flow behavior index increased with the decrease of consistency coefficient. At same temperature, the storage modulus $\mathrm{G}^{\prime}$ was greater when the protein content was higher.
\end{abstract}

Keywords: starch, amylose, protein, content, pasting.

\section{Introduction}

Starch is generally applied in food processing. Pasting and rheological properties are important physical and chemical characteristics of starch, and consistency coefficient, flow-behavior index and yield stress are all important parameters of rheological properties. The rheological properties of liquid foods of starch will affect the quality of foods, such as hardness, stickiness, chewiness, etc. There is close relationship between the rheological properties of materials and its transportation, agitation, mixing and energy consumption. There have been many international and domestic studies on the factors affecting rheological properties of rice starch paste, rheological properties during the aging of rice starch paste, rheological properties of rice amylopectin, rheological properties of rice starch during the storage, rheological properties of modified rice starch, effects of food additives on rheological properties of rice starch, etc. It is considered that rice starch is composed of long-chain amylose and

* Corresponding author. 
amylopectin, rice starch paste is a kind of pseudoplastic fluid with the property of shear thinning, which, generally, is beneficial for the application and processing. In certain range of shear rate, it can greatly decrease the viscosity of the materials and increase its fluidity so as to benefit the pumping transportation and processing, decrease energy consumption and increase productivity. However, the shear shinning should be small in some processing procedures to ensure the stable viscosity of the materials in order to prevent the rapid change of viscosity caused by the fluctuation of shear rate to guarantee the quality of half-finished product or finished product. However, the rheological properties of different rice varieties are different due to the differences in the contents of amylose and amylopectin as well as the characteristics and molecular conformation of starch molecules. The recent studies suggested that, besides the content of amylose, the protein content also greatly affected starch pasting and rheological properties. For example, Lim (Lim et al., 1999) reported that reducing the protein content in rice flour increases its peak viscosity. This was confirmed by Tan and Corke (Tan et al., 2002) who proposed that protein content is negatively correlated to peak viscosity and hot paste viscosity. Furthermore, Lyon (Lyon et al., 2000) found that protein content was negatively correlated to adhesiveness of cooked rice. However, in most of these studies, the prolamin proteins extracted from rice was added into rice starch to observe the effects on rheological properties of rich starch, which only showed the relationship between total protein content and physical characteristics of rice but not the effect the intrinsic protein content in rich starch on rich starch pasting. In this study, the indica rice starch and japonica rice starch were prepared by soaking rice flour in sodium hydroxide solution and five protein contents of indica rice starch and japonica rice starch obtained from the changes of soaking time, meanwhile, the main purpose of our study is to further investigate the effects of rice varieties and protein contents on rich starch pasting and rheological properties.

\section{Materials and Methods}

\subsection{Starch Isolation}

Rice starch was isolated from rice flour by soaking rice flour $(10 \mathrm{~g})$ into sodium hydroxide solution $(0.2 \% \mathrm{w} / \mathrm{v} ; 200 \mathrm{ml})$ for $12 \mathrm{~h}$. The mixture was stirred at room temperature for $5 \mathrm{~min}$, the slurry was centrifuged at $6000 \mathrm{~g}$ for $5 \mathrm{~min}$ (Ibanez et al., 2007). The supernatant and any brown surface layer of the starch were removed and the lower white starch layer was washed with distilled water and centrifuged, the procedure was repeated for several time and the solid phase was washed using distilled water until the $\mathrm{pH}$ of the filtrate was 6.0-7.0. The solid phase was dried at $45{ }^{\circ} \mathrm{C}$ for $48 \mathrm{~h}$ in a vacuum oven and moisture was allowed to equilibrate to a level of $13 \%$. Pass through a 100-mesh sieve.

\subsection{Defatting of Rice Starch}

Starch samples were defatted before amylose determination in the experiments in order to minimize lipid contamination in the amylose determination. Defatting was carried 
out by adding 14 volumes of an ethyl ether/methanol (1:1; v/v) mixture to rice starch samples, and the resultant slurries were mixed thoroughly, allowed to stand for $1 \mathrm{~h}$ and centrifuged at $10000 \mathrm{~g}$ for $10 \mathrm{~min}$ (Chrastil et al., 1994). The defatting procedure was repeated a total of three times to maximize removal of the lipid components.

\subsection{Amylose Contents Determination}

Amylose contents were determined by fully automated flow injection system (FIAStar5000, FOSS, Ltd, Sweden.). This is a new type of continuous flow analysis technique. This technology is that a certain volume of sample solution is injected into a flowing and non-air spacing reagent solution (or water) containing the stream according to compared method and the work curve drawn by standard solution measured the concentration of a substance in the sample solution. After defatting, spread the rice starch in a thin layer on a dish or watch glass or place them in paper bags and leave for 2 days in the same room to allow evaporation of residual methanol and for moisture content equilibrium to be reached. Weigh in duplicate $100+/-0.5 \mathrm{mg}$ of the test sample into $100 \mathrm{ml}$ volumetric flasks. To the test portion, carefully add $1 \mathrm{ml}$ of ethanol $95 \%$ (V/V) using a pipette, washing down any of the test portion adhering to the side of the flask. Add $9.0 \mathrm{ml}$ of $1 \mathrm{~mol} / \mathrm{l}$ sodium hydroxide solution using a pipette and mix. Then heat the mixture in a boiling water bath for $10 \mathrm{~min}$ to disperse the amylose. Allow to cool to room temperature without shaking for at least $2 \mathrm{~h}$ (or over night). Make up to the metered volume with water and mix vigorously.

\subsection{Protein Content}

Protein content was calculated multiplying the nitrogen content of the starch sample by 6.25. The nitrogen content of starch was measured in duplicate with a Vario MARCO (Elementar Analysensysteme, Hanau, Germany).

\subsection{Pasting Properties}

The pasting properties of rice starch were determined with the Rapid Visco Analyzer (RVA super 4, Newport Scientific, Australia), and analyze with analysis software. Viscosities of starches were recorded with starch suspensions (Moisture Content 12.0\%, sample $3.00 \mathrm{~g}$, water $25.00 \mathrm{~mL}$ ). Underwent a controlled heating and cooling cycle under constant shear where it was held at $50{ }^{\circ} \mathrm{C}$ for $1 \mathrm{~min}$, heated from 50 to $95^{\circ} \mathrm{C}$ at $5{ }^{\circ} \mathrm{C} / \mathrm{min}$ and held at $95{ }^{\circ} \mathrm{C}$ for $2.7 \mathrm{~min}$, cooled from $95{ }^{\circ} \mathrm{C}$ to $50{ }^{\circ} \mathrm{C}$ at $5{ }^{\circ} \mathrm{C} / \mathrm{min}$ and held at $50{ }^{\circ} \mathrm{C}$ for $2 \mathrm{~min}$. The initial speed of blender in $10 \mathrm{~s}$ for $960 \mathrm{rpm}$, after that maintain $160 \mathrm{rpm}$. Viscosity value take Rapid Visco Units (RVU) for unit. Pasting parameters such as pasting temperature, peak viscosity, breakdown (peak viscosity-hot paste viscosity), final viscosity, setback (cold paste viscosity- peak viscosity) were recorded.

\subsection{Measurement of Flow Behavior}

Rice starch paste of $8 \%$ was put into the testing platform of dynamic rheometer (ARES, TA, Ltd, America). viscometry was performed using a controlled strain rheometer 
using parallel plate mould (40mm diameter and $1 \mathrm{~mm}$ gap). After trimming off the over-loaded portion of samples around plates, the open side of samples was covered with a thin layer of silicon oil to prevent moisture loss. Apparent viscosity and shear stress with increasing shear rate $(0-500 \mathrm{~s}-1)$ were obtained at $20^{\circ} \mathrm{C}$ to characterize flow behavior. The Herschel-Bulkley equations (Rao, 1999) were fitted to obtain the parameters of flow curves. The multiple correlation coefficients, R2, show the degree of fitting of the Herschel-Bulkley model:

$$
\tau=\tau_{0+\mathrm{K}} \gamma_{\mathrm{n}} \quad \mathrm{K}, \mathrm{n} \text { is constant }
$$

Where $\tau$ is the shear stress $(\mathrm{Pa}),{ }^{\cdot} \tau 0$ is the yield stress $(\mathrm{Pa}), \mathrm{K}$ is the consistency index (Pa.sn), $\gamma$ is the shear rate (s-1), and $\mathrm{n}$ is the flow behavior index.

\subsection{Measurement of Dynamic Viscoelasticity Behavior}

The rheological properties of rice starch were measured by dynamic rheometer (ARES, TA, Ltd, America). Rice starch suspension of $20 \%$ was put into the testing platform of dynamic rheometer, the plane mould diameter is $40 \mathrm{~mm}$ and oscillation measurement procedure were selected, clearance was set up for $1.0 \mathrm{~mm}$, the strain was $2 \%$ and the angle frequency was $5 \mathrm{rad} / \mathrm{s}$. After trimming off the over-loaded portion of samples around plates, the open side of samples was covered with a thin layer of silicon oil to prevent moisture loss. Experiment process : procedure increase temperature are from $20^{\circ} \mathrm{C}$ to $100^{\circ} \mathrm{C}$, which enables suspension system of rice starch to become paste, and then procedure decrease temperature from $100^{\circ} \mathrm{C}$ to $20^{\circ} \mathrm{C}$, and then test the changes of the storage modulus $\left(G^{\prime}\right)$, loss modulus $\left(G^{\prime \prime}\right)$ and loss $\operatorname{tangent} \tan \delta\left(\tan \delta=G^{\prime \prime} / G^{\prime}\right)$ of starch paste in the process of heating and cooling, the velocity of increasing and decreasing temperature respectively was $5^{\circ} \mathrm{C} / \mathrm{min}$.

\section{Results and Discussion}

\subsection{Chemical Composition Analysis of the Rice Starches}

Many factors may affect the pasting and rheological properties of rice starch, among which, rice varieties, fat content and protein content all play critical roles. In rice, the content of starch is $80 \%$ and fat content is about $1 \% \sim 3 \%$. However, the protein content is about $8 \%$ which is comparatively higher. The amylose content is different due to rice variety, which is one of the most important determinants of rice starch quality (Sudha et al., 2007). Therefore, the effects of amylose content and protein content on pasting and rheological properties of rice starch are particularly significant, and the effect of fat on starch characteristics is mainly due to the complexation between lipoids and amylose (Jean et al., 2008), which results in the decreasing in amylose content and affects the physical and chemical characteristics of starch at some degree. To perform defatting before experiment will minimize the effect of fat on starch characteristics. Indica rice starch and japonica rice starch were extracted by soaking rice flour into sodium 
hydroxide solution $(0.2 \%, \mathrm{w} / \mathrm{w})$, five protein contents $(0.52 \%, 0.86 \%, 0.95 \%, 1.10 \%$ and $1.20 \%$, respectively) were obtained through the changes of soaking time. The chemical compositions of indica rice starch and japonica rice starch are listed in Table1. As is shown in table1, there is not significant difference about the amylose content in the same rice starch with various protein contents.

Table 1. The chemical composition of indica rice starch and japonica rice starch

\begin{tabular}{ccccc}
\hline \multirow{2}{*}{ Sample } & $\begin{array}{c}\text { Moisture } \\
(\%)\end{array}$ & $\begin{array}{c}\text { Fat content } \\
(\%)\end{array}$ & $\begin{array}{c}\text { Protein content } \\
(\%)\end{array}$ & $\begin{array}{c}\text { Amylose content } \\
(\%)\end{array}$ \\
\hline indica rice starch & 13.2 & 0.48 & 0.52 & 29.5 \\
& & & 0.86 & 29.5 \\
& & & 0.95 & 29.5 \\
japonica rice starch & \multirow{2}{*}{13.0} & \multirow{2}{*}{0.47} & 1.10 & 29.6 \\
& & & 1.20 & 29.5 \\
& & & 0.52 & 24.5 \\
& & & 0.86 & 24.5 \\
& & & 1.10 & 24.5 \\
& & & 1.20 & 24.5 \\
\hline
\end{tabular}

\subsection{Effects of Rice Varieties and Protein Content on Pasting Properties of Rice Starch Paste}

The amylose content is different from different rice varieties, and the amylose content directly affects the pasting properties of starch. As is shown in Table2., for indica rice starch and japonica rice starch, when the protein contents were both $0.52 \%$, but amylose contents were $29.5 \%$ and $24.5 \%$, respectively, the pasting temperatures of indica rice starch and japonica rice starch were $82^{\circ} \mathrm{C}$ and $78^{\circ} \mathrm{C}$, respectively, and the peak viscosity and breakdown viscosity of indica rice starch were lower than those of japonica rice starch, however, the final viscosity and setback viscosity of indica rice starch were higher than those of japonica rice starch, and the peak viscosity, breakdown viscosity, final viscosity and setback viscosity of indica rice starch were 5304, 3479, 4748 and -556RVU, repectively, and those of japonica rice starch were 5923, 3974, 4560 and -1363RVU, respectively. The bonding force between amylose molecules are strong due to the hydrogen bonds (John et al., 2008), and the pasting of starch with high amylose content was difficult than that of starch with low amylose content, therefore, the pasting temperature of indica rice starch was higher than that of japonica rice starch. The peak viscosity and breakdown viscosity of starch were negatively correlated with the amylose content, this is consistent with previous reports (El-Kha-yat et al., 2003; Varavinit et al., 2003), the starch granules swell with the increasing of temperature and the amylose in starch granules obstruct the swelling, thus, the peak viscosity and breakdown viscosity decrease with the increaseing of amylose content. The setback viscosity of indica rice starch was significantly higher than that of japonica rice starch, 
which suggested that indica rice starch is more liable to aging than japonica rice starch, in which, the aging is mainly due to amylose because the molecular movement of starch molecules of pasting slows down at low temperature and the amylose molecules trends to arrange parallelly and draw close to each other to combine through hydrogen bonds so that the starch with high amylose content is easy to retrogradation (Kyoko et al., 2007 ) and its final viscosity is also comparatively higher. As was shown by the RVA curves in Figure.1, the changing tendency of pasting properties of indica rice starch and japonica rice starch were substantially consistent when their protein content were both $0.52 \%$, the viscosity increased with the increase of temperature during heating, and the viscosity began to decrease with further increase of temperature when the viscosity arrived the maximum value. During cooling, the viscosity of starch increased with the decreasing of temperature. In these processes, the starch molecules in starch granules combine to particle structures through hydrogen bonds, the strength of hydrogen bond decreases in hot water, the granules swell after absorbing water, the viscosity increase to the maximum value, Continued to heat, hydrogen bond and granules rupture, and a great amount of amylose leached out so that the viscosity decreases (Graeme et al., 2004). In the following cooling process, amylose begins to retrogradation with the decreasing of temperature and the hydrogen bonds between the chains of the molecules form again, which caused a significant increase in viscosity.

Table 2. Pasting properties of indica rice starch and japonica rice starch of different varieties and different protein content

\begin{tabular}{cccccccc}
\hline \multirow{2}{*}{ Sample } & $\begin{array}{c}\text { protein } \\
\text { content/\% }\end{array}$ & $\begin{array}{c}\text { Amylose } \\
\text { content/\% }\end{array}$ & PeakVisco & $\begin{array}{c}\text { Break- } \\
\text { down } \\
\text { (RVU) }\end{array}$ & $\begin{array}{c}\text { FinalVisco } \\
\text { (RVU) }\end{array}$ & $\begin{array}{c}\text { Setback } \\
\text { (RVU) }\end{array}$ & $\begin{array}{c}\text { Pasting } \\
\text { Temp/0C }\end{array}$ \\
\hline \multirow{2}{*}{ indica } & 0.52 & 29.5 & 5304 & 3479 & 4748 & -556 & 82 \\
rice starch & 0.86 & 29.5 & 5247 & 3384 & 3960 & -530 & 82 \\
& 0.95 & 29.5 & 5237 & 3255 & 3755 & -485 & 82 \\
& 1.10 & 29.6 & 5119 & 3004 & 3520 & -369 & 82 \\
& 1.20 & 29.5 & 4601 & 2663 & 3515 & -286 & 82 \\
japonica & 0.52 & 24.5 & 5923 & 3974 & 4560 & -1363 & 78 \\
rice starch & 0.86 & 24.5 & 5864 & 3744 & 3785 & -1267 & 78 \\
& 0.95 & 24.5 & 5778 & 3551 & 3590 & -1188 & 78 \\
& 1.10 & 24.5 & 5423 & 3148 & 3515 & -908 & 78 \\
& 1.20 & 24.5 & 5349 & 2867 & 3455 & -894 & 78 \\
\hline
\end{tabular}

—japonica rice starch ...indica rice starch

When the amylose contents were similar, rice starches with the different protein contents resulted significant difference in pasting properties, as was shown in Table2., protein content had little effect on pasting temperature, however, it significantly affected the peak viscosity, breakdown viscosity, final viscosity and setback viscosity of starch. Either for indica rice starch or for japonica rice starch, with the increasing of protein content in starch sample, the peak viscosity, breakdown viscosity and final viscosity of the starch all decreased significantly, however, the setback viscosity in- 
creased significantly. A decrease in the peak viscosity was also observed when prolamin were added to rice flour (Baxteer et al., 2004), likely due to the dilution effect of protein on the concentration of starch, since a negative correlation had been established between the protein content and the peak viscosity in rice flour (Lim et al., 1999; Tan et al., 2002). When the protein contents in indica rice starch and japonica rice starch increased from $0.52 \%$ to $1.20 \%$, the breakdown viscosity and final viscosity of indica rice starch decreased from 3479 to $2663 \mathrm{RVU}$ and from 4748 to $3515 \mathrm{RVU}$, respectively, and the breakdown viscosity and final viscosity of japonica rice starch decreased from 3974 to $2867 \mathrm{RVU}$ and from 4560 to $3455 \mathrm{RVU}$, respectively. The breakdown is related to the ability of the starched to withstand heating at high temperature and shear stress, the decrease in breakdown viscosity might be due to the failure of complete pasting and swelling of starch granules induced by the reduction of water-absorption of starch granules caused by water-absorption of protein during pasting (Cristina et al., 2008). In the cooling process, the starch molecules without completely pasting and swelling could not rearrange regularly so that the final viscosity of starch paste decreased. In the studies on starch, the increase of setback viscosity usually related to the crystallization of amylose chains is caused by the liability of protein ease to retrogradation.

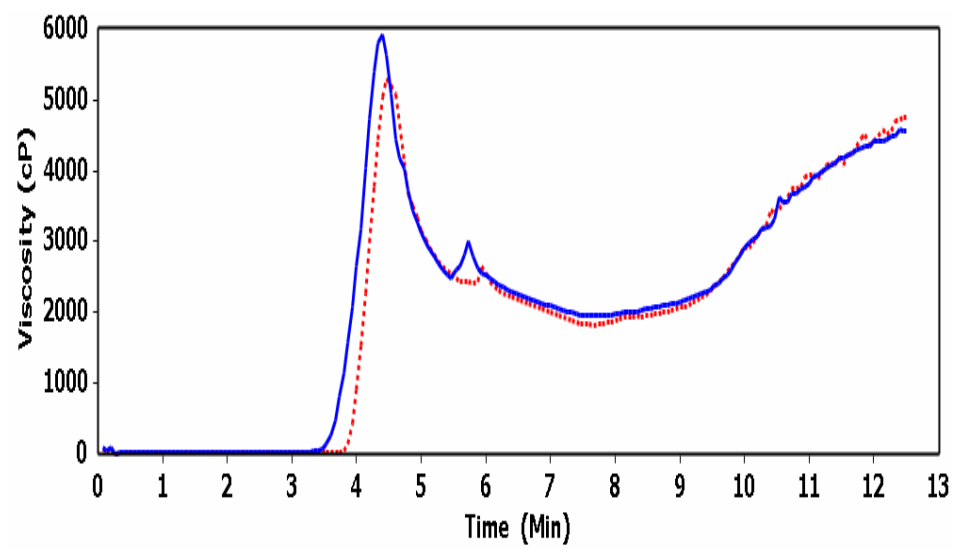

Fig. 1. RVA pasting curve of indica rice starch and japonica rice starch

\subsection{Effect of Rice Varieties and Protein Content on Flowing Characteristics of Rice Starch Paste}

The results from the previous studies indicated that high values of shear stress pointed to a high stability of the structural of the starch (Gibinski et al., 2006). According to that criterion, as was shown in Table3. and Figure.3, japonica rice starch had the more stable structure than indica rice starch. The flow behavior index, $n$, informed on the deviation from the Newtonian flow, for which $\mathrm{n}=1$. That parameter for rice starch was below 1 pointing that the rice starches were pseudoplastic and shear thinning liquids 
(Steffe, 1996), and its flow behavior index is below 1, which suggests that it is non-Newtonian fluid, the non-Newtonian behavior of starch solution was reported by many other researches (Evans et al., 1979; Nurul et al., 1999; Rao et al, 1997 ). As was shown by the flow curves in Figure 2, indica rice starch and japonica rice starch with different protein contents both presented shear shinning phenomenon which is the specific phenomenon of pseudoplastic fluid, the phenomenon suggested the decrease of apparent viscosity of the fluid with the increase of shear rate, the decrease with the increase of shear rate was quickly at the beginning, however, the decrease rate turned to stable gradually with the increase of shear rate when the apparent viscosity decreased to certain value, the apparent viscosity of japonica rice starch was greater than that of indica rice starch at the same shear rate, and the apparent viscosities of indica rice starch and japonica rice starch with protein content of $0.86 \%$ were highest at the same shear rate. As was shown by the flow curves in Figure.3, for the indica rice starch and japonica rice starch with different protein contents, the shear stress increased with the increase of shear rate, which was consistent with the characteristics of pseudoplastic fluid. It is accepted that the viscosity of a liquid is a function of the intermolecular forces that restrict molecular motion (Nurul et al., 1999). With the increasing of shear rate, disentanglement of long chain molecules occurs, as a result, the intermolecular resistance to flow (viscosity) is reduced, meanwhile, the highly solvated molecules or particles presented in the dispersion medium might be progressively sheared away with increasing shear rate causing a reduction in the effective size of the particles and hence a reduction apparent viscosity of starch (Bhandari et al., 2002; Holdsworth, 1971). The previous studies suggested that the viscosity of starch solution resulted from swelling starch granules and amylose leached out from the granules (Yue et al, 2008). For the starch with high protein content, the starch granules can not absorb adequate water to swell due to the dilution effect of protein, therefore, at the same shear rate, the apparent viscosity of starch decreased with the increasing of protein content. For the starch with high amylose content, the joint points among starch molecules usually trend to decrease and the shear stress between schlieres also decrease with the increasing of shear rate so that the apparent viscosity decreased.

The Herschel-Bulkley model flow curve parameters of different varieties of rice starch with different protein contents obtained with regression analysis were listed in Table3. The correlation coefficients were all among 0.985 0.999, which suggested that it was suitable to fit the flow curves of these rice starches with Herschel-Bulkley equation. For these rheological parameters, with the same protein content, the yield stress value of japonica rice starch was higher than that of indica rice starch. When the protein contents in indica rice starch and japonica rice starch increased from $0.52 \%$ to $1.20 \%$, their yield stress values decreased from 85.84 to $51.24 \mathrm{~Pa}$ and from 90.67 to $55.86 \mathrm{~Pa}$, respectively. Yield stress refers to the limited stress required for the initiation of flow. Consistency coefficient, K, from the Herschel-Bulkley model can also be taken as a viscosity criterion. With the same protein content, the consistency coefficient of japonica rice starch was higher than that fo indica rice starch. With the increase of protein content, the consistency coefficient of starch decreased, in which, the yield 
stress decreased with the decrease of interaction among starch molecules limiting the molecular movement. However, the change of flow behavior index was opposite, which increased with the decreasing of consistency coefficient. These results indicated that the indica rice starch with high amylose content and the starch with high protein content have good fluidity.

Table 3. Parameters of the Herschel-Bulkley models for the flow curves of rice starch with different varieties and diffetent protein contents

\begin{tabular}{cccccc}
\hline Sample & Protein content $(\%)$ & $\tau_{0(\mathrm{~Pa})}$ & $\mathrm{K}(\mathrm{Pa} . \mathrm{sn})$ & $\mathrm{n}$ & $\mathrm{R} 2$ \\
\hline indica rice starch & 0.52 & 85.84 & 88.85 & 0.252 & 0.998 \\
& 0.86 & 68.34 & 85.01 & 0.265 & 0.998 \\
& 0.95 & 56.594 & 75.33 & 0.299 & 0.997 \\
japonica rice starch & 1.10 & 55.450 & 64.05 & 0.334 & 0.993 \\
& 1.20 & 51.24 & 59.68 & 0.344 & 0.994 \\
& 0.52 & 90.67 & 171.2 & 0.236 & 0.993 \\
& 0.86 & 80.01 & 154.1 & 0.250 & 0.991 \\
& 0.95 & 69.93 & 132.95 & 0.267 & 0.985 \\
& 1.10 & 67.56 & 109.01 & 0.283 & 0.998 \\
& 1.20 & 55.86 & 101.1 & 0.287 & 0.988 \\
\hline
\end{tabular}
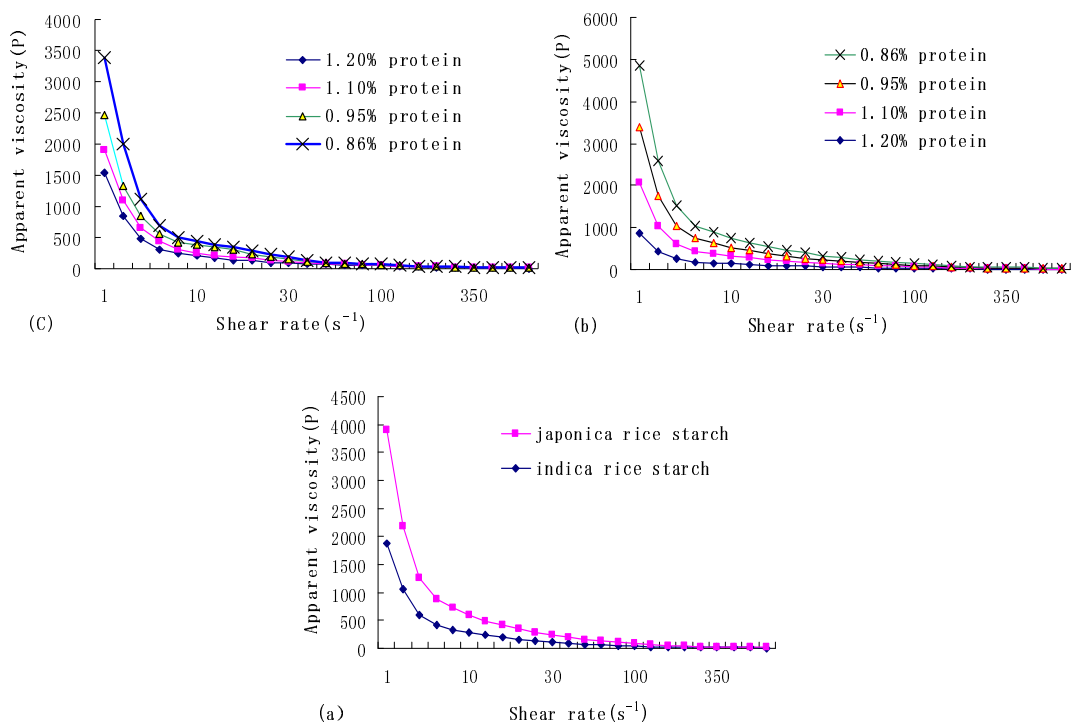

Fig. 2. Apparent viscosity as a function of shear rate for starches of different varieties and different protein contents: (a) indica rice starch and japonica rice starch with same protein content, (b) japonica rice starch with different protein contents, (c) indica rice starch with different protein contents. 

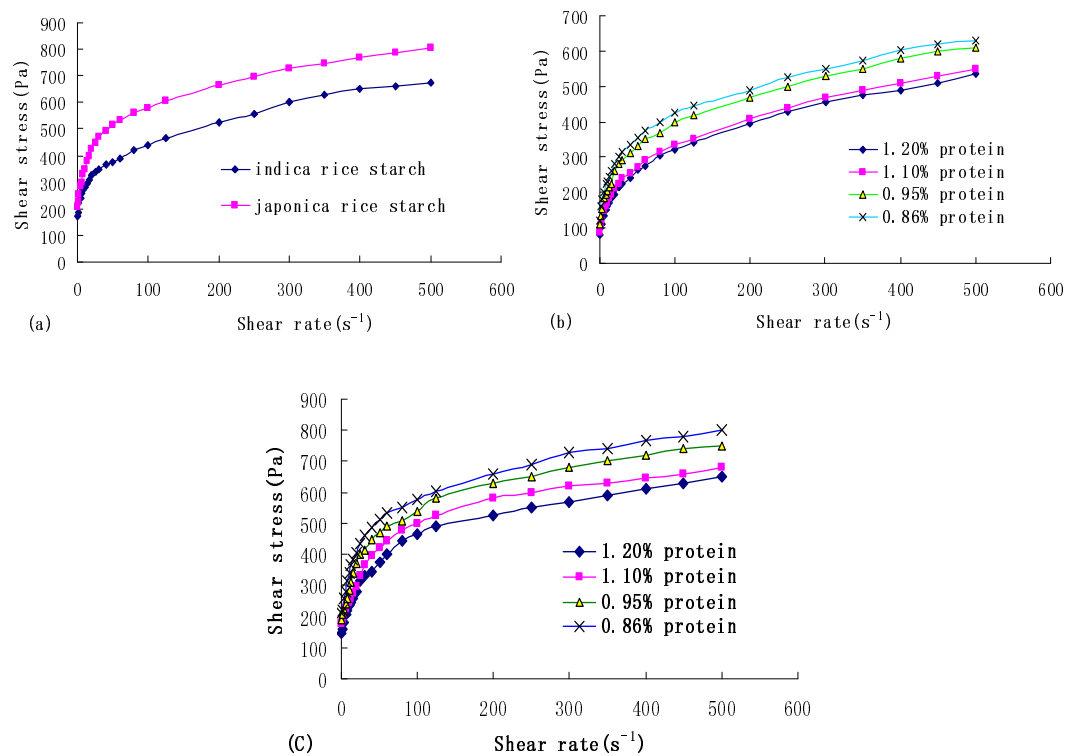

Fig. 3. Shear stress as a function of shear rate for starches of different varieties and different protein contents: (a) indica rice starch and japonica rice starch with same protein content, (b) japonica rice starch with different protein contents, (c) indica rice starch with different protein contents.

\subsection{Effects of Rice Varieties and Protein Content on Viscoelastic Properties of Rice Starch Paste}

The rheological properties of starch were measured by dynamic rheometer, then, the storage modulus $\mathrm{G}^{\prime}$ and loss tangent $\tan \delta\left(\tan \delta=\mathrm{G}^{\prime \prime} / \mathrm{G}^{\prime}\right)$ changing with temperature were determined by the dynamic oscillation measurement procedure of the rheometer, among which, the storage modulus $\left(G^{\prime}\right)$ represented the elastic properties of rice starch paste and the loss modulus $\left(G^{\prime \prime}\right)$ represented the viscosity properties. In the dynamic measurement with rheometer, the changes of storage modulus $\mathrm{G}^{\prime}$ can reflect the changes of hardness and strength of the gel, and the greater $G^{\prime}$ means higher hardness and strength (Rao et al., 1997). The changes of loss modulus G" can reflect the changes of viscosity properties of the gel, and The changes of loss tangent $\tan \delta$ can reflect the changes of viscoelastic properties of the gel, lower $\tan \delta$ value means that the elasticity of the gel is greater than the viscosity; conversely, the viscosity is greater than the elasticity.

The changes of storage modulus G' and loss tangent tan $\delta$ of indica rice starch and japonica rice starch with different protein contents in the processes of heating and cooling were listed in Table4. As was shown in Table4, during heating, the storage modulus $\mathrm{G}^{\prime}$ of indica rice starch and japonica rice starch increased greatly at a certain temperature to a maximum and then dropped with continued heating. In the cooling process, $G^{\prime}$ increased with the decreasing of temperature. With the same concentration, 
protein content and changing rate of temperature, the storage modulus $\mathrm{G}^{\prime}$ of indica rice starch was higher than that of japonica rice starch. The gels of all high amylose content rice starches have been credited with higher $\mathrm{G}^{\prime}$ indicating a well-cross-linked network structures and increase in $\mathrm{G}^{\prime}$ followed an exponential relationship with amylose content (Biliaderis et al., 1993). A significant increase in $\mathrm{G}^{\prime}$ of rice starch on heating is caused by formation of a three-dimensional (3D) gel network developed by leached out amylose and reinforced by strong interaction among the swollen starch particles (Hsu et al., 2000; Vasanthan et al., 1996). The decreasing of $G^{\prime}$ might be attributed to the melting of the remaining crystallites, which resulted in swelling granules to become softer. In the cooling process, the amylose molecules cross linked through hydrogen bonds and formed the binding area, which enhanced the starch gel network and resulted the increase of G'. The response process of G" was similar as that of G' value.

Table 4. Effect of different varieties and different protein contents on the rice starch rheological parameters $\left[\mathrm{G}^{\prime}(\mathrm{Pa})\right]$

\begin{tabular}{|c|c|c|c|c|c|c|c|c|c|c|c|c|c|}
\hline \multirow{2}{*}{ Sample } & \multirow{2}{*}{$\begin{array}{c}\text { Protein } \\
\text { content } \\
(\%)\end{array}$} & \multirow{2}{*}{ Parameters } & \multicolumn{11}{|c|}{ Temperature $\left({ }^{0} \mathrm{C}\right)$} \\
\hline & & & 50 & 60 & 70 & 80 & 90 & 100 & 90 & 80 & 70 & 60 & 50 \\
\hline \multirow{8}{*}{$\begin{array}{l}\text { Indica } \\
\text { rices tarch }\end{array}$} & 0.86 & $\mathrm{G}^{\prime}(\times 103)$ & 1.1 & 1.7 & 2.1 & 4.7 & 3.8 & 2.6 & 4.2 & 5.5 & 7.2 & 9.1 & 11 \\
\hline & & $\tan \delta$ & 0.19 & 0.21 & 0.19 & 0.18 & 0.17 & 0.16 & 0.17 & 0.18 & 0.19 & 0.2 & 0.21 \\
\hline & 0.95 & $\mathrm{G}^{\prime}(\times 103)$ & 1.5 & 2.0 & 2.4 & 4.9 & 4.1 & 2.8 & 5.4 & 7.6 & 9.6 & 12 & 14 \\
\hline & & $\tan \delta$ & 0.2 & 0.23 & 0.25 & 0.21 & 0.2 & 0.19 & 0.22 & 0.23 & 0.23 & 0.24 & 0.24 \\
\hline & 1.10 & $\mathrm{G}^{\prime}(\times 103)$ & 1.8 & 2.2 & 2.6 & 5.1 & 4.3 & 3.1 & 6.5 & 8.6 & 11 & 14 & 18 \\
\hline & & $\tan \delta$ & 0.24 & 0.3 & 0.25 & 0.24 & 0.21 & 0.19 & 0.18 & 0.19 & 0.2 & 0.21 & 0.22 \\
\hline & 1.20 & $\mathrm{G}^{\prime}(\times 103)$ & 2.1 & 2.4 & 2.8 & 6.8 & 5.1 & 3.5 & 7.6 & 11 & 15 & 20 & 26 \\
\hline & & $\tan \delta$ & 0.26 & 0.35 & 0.31 & 0.22 & 0.21 & 0.21 & 0.22 & 0.23 & 0.24 & 0.25 & 0.26 \\
\hline \multirow{8}{*}{$\begin{array}{l}\text { Japonica } \\
\text { rice starch }\end{array}$} & 0.86 & $\mathrm{G}^{\prime}(\times 103)$ & 1.0 & 1.6 & 1.9 & 3.9 & 3.1 & 1.7 & 2.5 & 3.8 & 5.3 & 7.3 & 9 \\
\hline & & $\tan \delta$ & 0.18 & 0.19 & 0.18 & 0.17 & 0.16 & 0.16 & 0.17 & 0.18 & 0.19 & 0.2 & 0.21 \\
\hline & 0.95 & $\mathrm{G}^{\prime}(\times 103)$ & 1.3 & 1.8 & 2.1 & 4.2 & 3.3 & 2.2 & 2.9 & 4.5 & 6.3 & 8.2 & 10 \\
\hline & & $\tan \delta$ & 0.19 & 0.2 & 0.21 & 0.19 & 0.18 & 0.17 & 0.19 & 0.21 & 0.22 & 0.23 & 0.23 \\
\hline & 1.10 & $\mathrm{G}^{\prime}(\times 103)$ & 1.5 & 2.0 & 2.4 & 4.5 & 3.5 & 2.4 & 3.1 & 4.8 & 6.8 & 8.8 & 11 \\
\hline & & $\tan \delta$ & 0.17 & 0.21 & 0.2 & 0.19 & 0.18 & 0.17 & 0.18 & 0.19 & 0.2 & 0.21 & 0.22 \\
\hline & 1.20 & $\mathrm{G}^{\prime}(\times 103)$ & 1.9 & 2.2 & 2.6 & 4.7 & 3.8 & 2.6 & 3.8 & 5.7 & 7.8 & 10 & 12 \\
\hline & & $\tan \delta$ & 0.21 & 0.22 & 0.25 & 0.24 & 0.22 & 0.21 & 0.22 & 0.23 & 0.24 & 0.25 & 0.25 \\
\hline
\end{tabular}

At same temperature, the $\mathrm{G}^{\prime}$ value decreased with the decrease of protein content. The loss tangent $\tan \delta$ were all less than 0.4 , which suggested that $G^{\prime}$ values were all greater than G" values and the hardness and strength of starch gel were high. In the hearting process, the starch granules could not absorb adequate water to swell due to the water-absorption of protein so that the viscosity decreased. In the cooling process, the protein enhanced the formation of gel network which increased the hardness and strength of the starch paste.

\section{Conclusion}

The amylose content varies in the starches of different rice varieties. For the effects of rice varieties on rice starch pasting and rheological properties, besides the size and the swelling degree of the starch granules, amylose content is also a critical factor. For the 
starches with similar amylose contents but different protein contents, there are significant differences between their pasting and rheological properties. The pasting temperature of indica rice starch is $82^{\circ} \mathrm{C}$ and the pasting temperature of japonica rice starch is $78^{\circ} \mathrm{C}$. When the protein contents were same, the peak viscosity and breakdown viscosity of indica rice starch were lower than those of japonica rice starch, however, the final viscosity and setback viscosity of indica rice starch were higher than those of japonica rice starch. The peak viscosity, breakdown viscosity, final viscosity and setback viscosity of indica rice starch with protein content of $0.52 \%$ were 5304,3479 , 4748 and -556RVU, respectively, and the peak viscosity, breakdown viscosity, final viscosity and setback viscosity of japonica rice starch were 5923, 3974, 4560 and -1363RVU, respectively. With the increase of protein content in starch samples, the peak viscosity, breakdown viscosity and final viscosity of the starch all decreased significantly, but the setback viscosity of the starch increased significantly. With the same protein content, the consistency coefficient value of japonica rice starch was higher than that of indica rice starch, and the consistency coefficient of starch decreased with the increase of protein, however, the flowing-behavior index increased with the decrease of consistency coefficient. With the same protein content and changing rate of temperature, the storage modulus $G^{\prime}$ of indica rice starch was higher than that of japonica rice starch. The $\mathrm{G}^{\prime}$ value decreased with the decrease of protein content. Loss factor $\tan \delta$ were all less than 0.4 , which suggested that $\mathrm{G}^{\prime}$ values were all greater than $\mathrm{G}^{\prime \prime}$ values, the hardness and strength of starch gel were high, and the starch paste showed solid-like behaviors.

\section{Acknowledgements}

The authors gratefully acknowledge the financial support of the National Hi-Tech Research and Development Program of China (Grant No. 2006AA10Z341), and Science Foundation of Hunan Province (Grant No. 2007FJ1007).

\section{References}

Ibanez, A.M., Wood, D.F., Yokoyama, W.H., et al.: Viscoelastic properties of waxy and nonwaxy rice flours, their fat and protein-free starch, and the microstructure of their cooked kernels. Journal of Agricultural and Food Chemistry 55, 6761-6771 (2007)

Graeme, B., Christopher, B., Zhao, J.: Effects of prolamin on the textural and pasting properties of rice flour and starch. Journal of Cereal Science 40, 205-211 (2004)

Lyon, B.G., Champagne, E.T., Vinyard, B.T., et al.: Sensory and instrumental relationships of texture of cooked rice from selected cultivars and postharvest handling practices. Cereal Chemistry 77, 64-69 (2000)

Biliaderis, C.G., Juliano, B.O.: Thermal and mechanical properties of concentrated rice starch gels of varying composition. Food Chemistry 48, 243-250 (1993)

Marco, C., Rosell, C.M.: Effect of different protein isolates and transglutaminase on rice flour properties. Journal of Food Engineering 84, 132-139 (2008)

Jean-Louis, D., Sylvie, D.A.: Rheological characterization of semi-solid dairy systems. Food Chemistry 108, 1169-1175 (2008) 
Baxter, G., Blanchard, C., Zhao, J.: Effects of prolamin on the textural and pasting properties of rice flour and starch. Journal of Cereal Science 40, 205-211 (2004)

El-Kha-yat, G., Samaan, J., Brennan, C.S.: Evaluation of vitreous and starchy Syrian durum (Triticum durum) wheat grains: the effect of amylose content on starch characteristics and flour pasting properties. Starch/Stärke 55, 358-365 (2003)

Lim, H.S., Lee, J.-H., Shin, D.-H.: Comparison of protein extraction solutions for rice starch isolation and effects of residual protein content on starch pasting properties. Starch/Stärke 51, 120-125 (1999)

Evans, I.D., Haisman, D.R.: Rheology of gelatinised starch suspensions. Journal of Texture Studies 10, 347-370 (1979)

Nurul, I.M., Azemi, B.M.N.M., Manan, D.M.A.: Rheological behavior of sago (Metroxylon sagu) starch paste. Food Chemistry 64, 501-505 (1999)

Chrastil, J., Zarins, Z.: Changes in peptide subunit composition of albumins, globulins, prolamins, and oryzenin in maturing rice grains. Journal of Agricultural and Food Chemistry 42, 2152-2155 (1994)

Steffe, J.M.: Rheological methods in food process engineering, 2nd edn., pp. 328-331. Freeman, East Lansing (1996)

Ohishi, K., Kasai, M., Shimada, A., et al.: Effects of acetic acid on the rice gelatinization and pasting properties of rice starch during cooking. Food Research International 40, 224-231 (2007)

Yue, L., Charles, F.S., Ma, J.G., et al.: Structure-viscosity relationships for starches from different rice varieties during heating. Food Chemistry 106, 1105-1112 (2008)

Gibinski, M., Kowalski, S., Sady, M., et al.: Thickening of sweet and sour sauces with various polysaccharide combinations. Journal of Food Engineering 75(3), 407-414 (2006)

Sudha, M.L., Vetrimani, R., Leelavathi, K.: Influence of fibre from different cereals on the rheological characteristics of wheat flour dough and on biscuit quality. Food Chemistry 100, 1365-1370 (2007)

Rao, M.A.: Rheology of fluid and semisolid foods - Principles and applications, pp. 7-59. An Aspen Publication, Gaithesburg (1999)

Rao, M.A., Okechukwu, P.E., Da Silva, et al.: Rheological behavior of heated starch dispersions in excess water: Role of starch granule. Carbohydrate Polymers 33, 273-283 (1997)

Bhandari, P.N., Singhal, R.S., Kale, D.D.: Effect of succinylation on the rheological profile of starch pastes. Carbohydrate Polymers 47, 365-371 (2002)

Holdsworth, S.D.: Applicability of rheological models to the interpretation of flow and processing behavior of fluid food products. Journal of Texture Studies 2, 393-418 (1971)

Hsu, S., Lu, S., Huang, C.: Viscoelastic changes of rice starch suspensions during gelatinization. Journal of Food Science 65, 215-220 (2000)

John, S., Mounsey, E.D., O'Riordan: Characteristics of imitation cheese containing native or modified rice starches. Food Hydrocolloids 58, 184-193 (2008)

Lim, S.-T., Lee, J.-H., Shin, D.H., et al.: Comparison of protein extraction solutions for rice starch isolation and effects of residual protein content on starch pasting properties. Starch 51, 120-125 (1999)

Varavinit, S., Shobsngob, S., Varanyanond, W., et al.: Effect of amylose content on gelatinization, retrogradation and pasting properties of flours from different cultivars of Thai rice. Starch/Stärke 55, 410-415 (2003)

Vasanthan, T., Bhatty, R.S.: Physicochemical properties of small- and large-granule starches of waxy, regular and high-amylose barleys. Cereal Chemistry 73, 199-207 (1996)

Tan, Y., Corke, H.: Factor analysis of physiochemical properties of 63 rice varieties. Journal of the Science of Food and Agriculture 82, 745-752 (2002) 